\title{
Analysis of Collision at Sea using Human Error Assessment and Reductive Technique (HEART) in Japan and Hong Kong
}

\author{
Ludfi Pratiwi Bowo ${ }^{\mathrm{a}, *}$ and Masao Furusho ${ }^{\mathrm{b}}$ \\ Graduate School of Maritime Sciences, Kobe Univerosty, Kobe, Japan \\ a.ludfi.bowo@gmail.com,b.furusho@maritime.kobe-u.ac.jp \\ *corresponding author
}

Keywords: Collision, Error-Producing Conditions (EPC), HEART Methodology, Human Factors.

Abstract: The abstract should summarize the contents of the paper and should contain at least 100 and at most 300 words. It should be set in 12-point font size. There should be a space before of 18-point and after of 60-point.

\section{Introduction}

Maritime accidents have been topic for many researchers to research how to reduce the number and make preventive actions, because maritime accidents are threat of the safety life at sea and for economic performance of shipping industry and the environment, for instance is collision. Therefore, the assessment of the situation which can lead to collision accident is important, in order to be a consideration for seafarers, because human factor is the main factor who lead the situation into accident. In $80 \%$ of maritime accidents were found that human factors have implicated on it [1]. Moreover several studies have identified the contribution of human factors to maritime accidents [2], [3].

International Maritime Organization (IMO) had established regulations regarding to avoid the collision, named The International Regulations for Preventing Collisions at Sea 1972 (COLREG) [4]. In 1974 to determine the minimum standard of construction, equipment and operation of ships which aims to create a safety of the life at sea, IMO held the convention namely Safety of Life at Sea (SOLAS) and 4 years later, in 1978 Standards of Training, Certification and Watchkeeping for Seafarers (STCW) was established, moreover there are amandmends of the coventions before and other convention which has aims to reduce the frequencies of occurrence of serious accidents in the maritime industry [5]. Those efforts have shown a slight decline every year, especially in Japan and Hong Kong Special Administrative Region of the People's Republic of China yet it is still high number.

In this study, Human Error Assessment and Reductive Technique (HEART) methodology is utilized. HEART methodology was first applied to assess accident in nuclear accident [6], [7], and develop to be applied in other industry sectors, aviation [8], railway industries [9] and marine 
operational [10]. The objectives of this study are to find the causes of collision in both Japan and Hong Kong Special Administrative Region of the People's Republic of China, to find the difference of the collision accidents between those two countries, and to apply the HEART methodology in various accidents. This paper is consisted of introduction, collision accidents data of Japan and Hong Kong, the description of HEART methodology, the results that obtained from data analysis, discussion and consideration, and the last one is conclusion.

\section{Collision Accidents Data}

In this study, the authors used the collision accident data from government of Japan and Hong Kong Special Administrative Region of the People's Republic of China which had been published on their official government website. The collision is defined by striking and being struck by another ship whether under way, mooring and anchoring, and also when ship striking the port facilities and marine life, which cause fatality and injuries.

\subsection{Japan's Collision Data}

The collision data from Japan are provided by the Japan Transportation Safety Board (JTSB) from period 2008 to 2016 in JTSB official website. JTSB is an organization belongs to Japanese Ministry of Land, Infrastructure, Transport and Tourism that conducts appropriate investigations into accidents and incidents in a scientific and objective manner, for aircraft, railway and marine. During the period of 2008-2016, there are 2,382 ship collisions recorded by JTSB, this is the highest number of maritime accidents in Japan, followed by grounding accident and occupational accident, meanwhile only several accidents that been fully reported because of the uncommon causes and some accidents that have same causes didn't fully reported again. There are 27 collision data were published in English report and these data have been used to be analyzed in this study. Table I below shows the collision data which consist of the date of occurrence, accidents time and the casualties and injuries that occurred, that have been used to be analyzed in this study. Based on those data, about $70 \%$ accidents occurred in the night time.

Table 2: Japan's Collision Accident Data.

\begin{tabular}{|c|c|c|c|}
\hline \multicolumn{4}{|c|}{ Japan's Collision Accident Data } \\
\hline $\begin{array}{c}\text { Case } \\
\text { Number }\end{array}$ & Date & $\begin{array}{c}\text { Accident's } \\
\text { Time }\end{array}$ & Casualties and Injuries \\
\hline 1 & $2008-7-22$ & $07: 42$ & There were no casualties. \\
\hline 2 & $2009-3-10$ & $02: 13$ & All of the crew of cargo ship went missing. \\
\hline 3 & $2009-2-20$ & $06: 15$ & There were no casualties. \\
\hline 4 & $2009-10-27$ & $19: 56$ & Six crews suffered injuries. \\
\hline 5 & $2010-3-28$ & $00: 11$ & A crew died, another went missing. \\
\hline 6 & 2011-8-19 & 04:39 & There were no casualties. \\
\hline 7 & 2011-9-11 & 04:40 & There were no casualties. \\
\hline 8 & 2011-11-27 & 04:58 & A crew went missing, the master was injured. \\
\hline 9 & $2011-7-6$ & $06: 14$ & The skipper died and a deckhand was injured. \\
\hline
\end{tabular}




\begin{tabular}{|c|c|c|c|}
\hline \multicolumn{4}{|c|}{ Japan's Collision Accident Data } \\
\hline $\begin{array}{c}\text { Case } \\
\text { Number }\end{array}$ & Date & $\begin{array}{c}\text { Accident's } \\
\text { Time }\end{array}$ & Casualties and Injuries \\
\hline 10 & $2012-7-16$ & 04:03 & There were no casualties. \\
\hline 11 & $2012-7-3$ & $07: 15$ & There were no casualties. \\
\hline 12 & $2012-3-8$ & $11: 01$ & The skipper was killed. \\
\hline 13 & $2012-2-7$ & $16: 22$ & There were no casualties. \\
\hline 14 & $2012-4-15$ & $20: 15$ & The skipper died, a crew went missing. \\
\hline 15 & $2012-9-24$ & $01: 56$ & Thirteen crews went missing. \\
\hline 16 & $2013-1-23$ & $23: 12$ & Four crew were slightly injured. \\
\hline 17 & $2013-6-15$ & 02:04 & There were no casualties. \\
\hline 18 & $2013-9-27$ & $01: 22$ & All crews were killed. \\
\hline 19 & $2013-6-23$ & $09: 44$ & The master went missing. \\
\hline 20 & $2013-2-25$ & 05:59 & The master and a crew were killed. \\
\hline 21 & $2013-1-10$ & $12: 19$ & There were no casualties. \\
\hline 22 & 2014-3-18 & 03:10 & Seven crews died, two crews went missing. \\
\hline 23 & $2014-11-15$ & $19: 19$ & There were no casualties. \\
\hline 24 & $2015-11-2$ & 21:09 & The master was injured. \\
\hline 25 & $2015-10-17$ & $03: 26$ & There were no casualties. \\
\hline 26 & $2016-1-8$ & $09: 54$ & Three passengers were seriously injured. \\
\hline 27 & 2016-2-19 & $23: 56$ & The skipper was killed. \\
\hline
\end{tabular}

\subsection{Hong Kong's Collision Data}

Furthermore, in Hong Kong, the Marine Department of the Government of the Hong Kong Special Administrative Region of the People's Republic of China is a department that responsible for all navigational matters and the safety standards of all classes and types of vessels. In total there are 1423 collisions within Hong Kong waters and 317 outside Hong Kong waters that have been recorded by the Marine Department of Hong Kong Government for the period of 2008-2014. Same as in Japan, in Hong Kong the collision is in the first place for the most common accidents which occurred during that period, followed by contact accident and grounding accident. According to accidents data report that has been issued, there are 21 data of collisions which written in English. From 21 data that has been collected, it is shown that for $28 \%$ passenger vessel is the most common vessel that occurred the collision accidents, following by container vessel and fishing vessel. Same as Japan. In Hong Kong collision accidents about $71 \%$ occurred in the night time. 
Table 2: Hong Kong's Collision Accident Data.

\begin{tabular}{|c|c|c|c|}
\hline \multicolumn{4}{|c|}{ Hong Kong's Collision Accidents Data } \\
\hline $\begin{array}{c}\text { Case } \\
\text { Number }\end{array}$ & Date & $\begin{array}{c}\text { Accident's } \\
\text { Time }\end{array}$ & Casualties and Injuries \\
\hline 1 & $2008-7-1$ & $20: 17$ & Eleven people were injured. \\
\hline 2 & $2008-9-2$ & $11: 42$ & The master was killed. \\
\hline 3 & $2008-3-5$ & 21:01 & There were no casualties. \\
\hline 4 & 2008-1-11 & $20: 28$ & 133 persons were injured. \\
\hline 5 & $2008-10-21$ & $05: 43$ & There were no casualties. \\
\hline 6 & $2008-3-22$ & $21: 13$ & Six crews were injured, 18 crews drowned. \\
\hline 7 & 2009-3-20 & $05: 27$ & Four crews died, three went missing. \\
\hline 8 & $2009-3-20$ & 03:44 & A passenger was killed. \\
\hline 9 & 2009-11-14 & $21: 47$ & 13 persons were slightly injured. \\
\hline 10 & $2010-12-7$ & 03:05 & Eight crews died. \\
\hline 11 & $2011-9-1$ & $04: 47$ & Six crews were injured. \\
\hline 12 & $2011-3-9$ & $21: 45$ & A coxswain was died. \\
\hline 13 & 2011-2-13 & $22: 37$ & Three crews were injured. \\
\hline 14 & $2011-6-26$ & $09: 35$ & Eleven people were injured. \\
\hline 15 & $2012-5-8$ & $13: 25$ & The coxswain went missing. \\
\hline 16 & $2012-5-13$ & $04: 18$ & One crew member went missing. \\
\hline 17 & $2012-4-9$ & $17: 39$ & One crew member went missing. \\
\hline 18 & $2013-11-5$ & $00: 51$ & Two crews were injured. \\
\hline 19 & 2014-10-29 & $23: 40$ & Thirteen crews went missing. \\
\hline 20 & $2014-8-24$ & $18: 53$ & Eleven crews went missing. \\
\hline 21 & $2014-12-25$ & $21: 17$ & One crew went missing. \\
\hline
\end{tabular}

Table 2 shows the date, time occurrence and the casualties and injuries of 21 collision data from Hong Kong that has been used in this study. According to the data, Hong Kong has more casualties that in Japan.

\section{Human Error Assessment and Reductive Technique (HEART) Methodology}

Human Error Assessment and Reductive Technique (HEART) methodology had been applied in several maritime accident types, such as grounding accidents which been the most common accidents in Canada [11], sink accidents, fire and explosion accidents which are the highest frequency of maritime accidents in Indonesia [12] and occupational accidents which occurred in Australia [13]. Basically, HEART methodology was developed to analyze the nuclear accidents since 1988 by William [6]. HEART methodology consists of two steps, the first one is qualitative step and the second one is quantitative step [14].

1) Qualitative step: In qualitative step, there is Generic Task which consist of 9 tasks that each of task has Nominal Human Unreliability (NHU). The highest number of NHU belongs to generic task A for totally unfamiliar, performed with no real idea of likely consequences. It is because with this condition, unfamiliarity, the probability of occurring accidents is higher than other generic task which they familiar with the situation or work but have no focus while working, not doing the task according to the procedures, etc. The generic task describe the working condition types before the accidents occurred. The more often and easier work which done by the seafarers, the number of 
nominal human unreliability is lower than if the working condition is more difficult and the seafarer is unfamiliar with the condition. Table 3 is shown the generic task that is used in this study.

Table 3: Generic Task.

\begin{tabular}{|l|l|}
\hline \multicolumn{2}{|c|}{ HEART Methodology Generic Task } \\
\hline (A) & Totally unfamiliar, performed at speed with no real idea of likely consequences. \\
\hline (B) & $\begin{array}{l}\text { Shift or restore system to a new state on a single attempt without supervision or } \\
\text { procedures. }\end{array}$ \\
\hline (C) & Complex task requiring high level of comprehension and skill. \\
\hline (D) & Fairly simple task performed rapidly or given scant attention. \\
\hline (E) & Routine, highly-practiced, rapid task involving relatively low level of skill. \\
\hline (F) & Restore or shift a system to new state following procedures, with some checking. \\
\hline (G) & Completely familiar, but without the benefit of significant job aids. \\
\hline (H) & $\begin{array}{l}\text { Respond correctly to system command even when there is an augmented supervisory } \\
\text { system providing accurate interpretation of system stage. }\end{array}$ \\
\hline (M) & Miscellaneous task for which no description can be found. \\
\hline
\end{tabular}

Figure 1 is shown the NHU belongs to each Generic Task. NHU has the maximum number, minimum number and average number. The bounds are used to calculate the upper and lower limits for the Human Error Probability (HEP) [8]. In this study, the author use the average number for calculation.

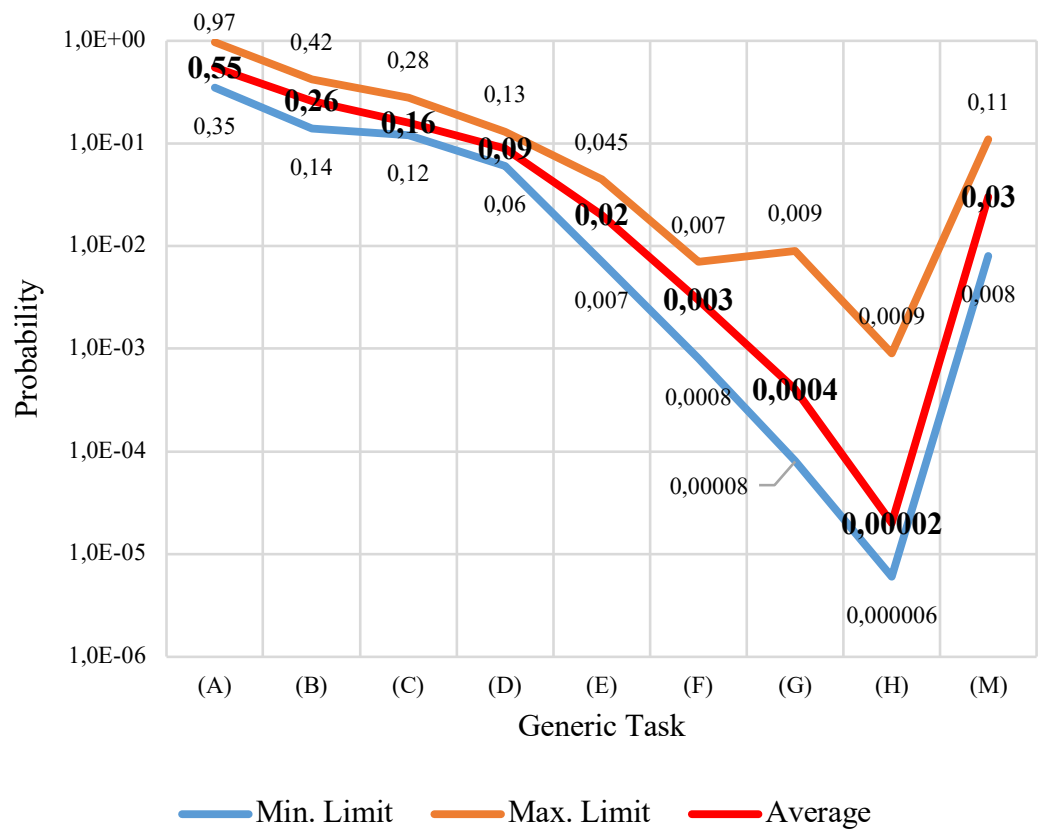

Figure 1: Nominal Human Unreliability of HEART Methodology Generic Task. 
And followed by determining Error-Producing Conditions (EPC) which represent the unsafe acts of the seafarer, which lead to accidents. The EPC is detail factors that appeared in particular accidents, consequently each accident has different EPC among others, but there are some typical EPCs that the same between mostly of the accidents. There are 38 EPCs that had been used in this study, that EPCs was established by William. Each of EPC has multiplier which will be used to calculate in the quantitative step. The multipliers consist of the highest number to the lowest number, which is the highest is 17 for EPC number 1 and the lowest is 1.02 for EPC number 38 . After determining the EPC that involved in the accidents, it needs to be assigned the number of Assessed Proportion Effect (APE) of each EPC which represent the entanglement of EPC in the accident. This APE will be used in the quantitative step.

2) Quantitative step: The second step of HEART methodology is calculating process. The last calculating result of this methodology is Human Error Probability (HEP), to obtain the HEP, the Assessed Impact Value (AIV) has to be calculated first by using the following formula:

$$
\mathrm{AIV}=((\text { EPC Multiplier }-1) \times \mathrm{APE})+1
$$

The result of AIV is only for one EPC, therefore the AIV of all EPC have to be calculated. After obtaining the result of AIV, it will be used for HEP calculation:

$$
\mathrm{HEP}=\mathrm{NHU} \times \mathrm{AIV}_{1} \times \mathrm{AIV}_{2} \times \ldots \times \mathrm{AIV}_{\mathrm{n}}
$$

To calculate the HEP, it is required the Nominal Human Unreliability (NHU) from the generic task that has been determined before, and the number of AIV. The result of HEP will show how big the influence of human in that certain accidents. the final result of the HEP is between 0 and 1 , which show that there is probability of other factors that influence the accident.

\section{Results}

\subsection{Ship's Type}

From 27 data of collision accidents in Japan that has been analyzed, there are 54 ships that involved the collision in periods 2008 to 2016 . Where the highest number of ships involved is cargo vessel for $35 \%$ and the second highest number is fishing vessel for $26 \%$, and then followed by container vessel, tanker vessel, vehicle carrier, passenger vessel and other respectively. Meanwhile in Hong Kong, there are 43 ships which occurred in the accidents from 21 cases that has been analyzed from 2008-2014 data. 
Table 4: Ship's Type

\begin{tabular}{|l|c|l|c|}
\hline \multicolumn{2}{|c|}{ Japan } & \multicolumn{2}{c|}{ Hong Kong } \\
\hline Ship's Type & \% & \multicolumn{1}{c|}{ Ship's Type } & \% \\
\hline Cargo Vessel & 35 & Passenger Vessel & 28 \\
\hline Fishing Vessel & 26 & Container Vessel & 19 \\
\hline Container Vessel & 19 & Fishing Vessel & 16 \\
\hline Tanker Vessel & 11 & Bulk Carrier & 12 \\
\hline Vehicle Carrier & 4 & Cargo vessel & 9 \\
\hline Passenger Vessel & 2 & Tug Boat & 5 \\
\hline Others & 4 & Others & 12 \\
\hline
\end{tabular}

In Hong Kong, the highest number of ships that involved in collision accident is Passenger vessel, for $28 \%$ from all of the ships total, it is different from collision in Japan, and then followed by container vessel, fishing vessel, bulk carrier, cargo vessel, tug boat and others, respectively. The data is shown in the Table IV.

\subsection{Generic Tasks}

Generic task is kind of task that the seafarers did right before the accidents occurred. Where the classification of task is differed by 9 tasks according to HEART methodology. In this study, there are 3 types of generic task that appeared in the situation right before the accident. The most common generic tasks that appear are fairly simple task performed rapidly or given scant attention and complex task requiring high level of comprehension and skill. But the most common generic task which appeared is different in Japan and in Hong Kong.

Table 5 shows the result of generic task that obtained in Japan's collision assessment, where fairly simple task performed rapidly or given scant attention is the most common generic task, and then followed by complex task requiring high level of comprehension and skill. From 27 cases, 17 cases proceed the fairly simple task performed rapidly or given scant attention, it means that mostly the work that being done by the seafarers right before the accidents are not complex task, but the seafarers do it with no or little attention and focus.

Meanwhile in Hong Kong, it is the opposite of Japan generic task, where mostly the accidents happened in complex task. It can be happened because the seafarers didn't have enough knowledge or training to encounter such difficult task on board. The result is shown in Table 6.

Table 5: Generic Task of Japan's Collision.

\begin{tabular}{|l|c|}
\hline \multicolumn{1}{|c|}{ Generic Task } & Cases \\
\hline (D) Fairly simple task performed rapidly or given scant attention. & 17 \\
\hline (C) Complex task requiring high level of comprehension and skill. & 10 \\
\hline
\end{tabular}


Table 6: Generic Task of Hong Kong Collision.

\begin{tabular}{|l|c|}
\hline \multicolumn{1}{|c|}{ Hong Kong Generic Task } & Cases \\
\hline (C) Complex task requiring high level of comprehension and skill. & 11 \\
\hline (D) Fairly simple task performed rapidly or given scant attention. & 10 \\
\hline
\end{tabular}

In the maritime accidents, the weather and the maritime traffic also took place into account. Therefore, if in the case it was stated that the weather condition was bad and or the maritime traffic was very dense, the generic task that determined also has higher nominal human unreliability, because in that situation, the human performance is very important to maintain the shipping to keep safe, in other words more complex task.

\subsection{Error-Producing Conditions}

The amount of EPC type that obtained both from Japan and Hong Kong are 19 out of 38 EPC and 21 out of 38 EPC respectively. In Japan's accident collisions there are 101 EPC in total for 27 cases, and 115 EPC for 21 cases that occurred in Hong Kong. Mostly the EPC type that obtain in Japan and Hong Kong is same, as much as 16 EPC types, but there are some differences of EPC type, because some particular cases. The rest of other EPC that obtained from this study is shown in this Table 7.

In Japan's collision cases, inadequate checking is taking place as the most common EPC that appeared. Inadequate checking also the most common EPC type that appeared in Hong Kong. In general, time shortage, inadequate checking and impoverished information among the seafarers are the most common EPC that appeared in the collision accidents in Japan and Hong Kong. EPC 27 (physical capabilities) and EPC 22 (lack of experience) are only appeared in Hong Kong collision accidents.

Table 7. Error-Producing Conditions

\begin{tabular}{|c|l|c|c|l|c|}
\hline \multicolumn{4}{|c|}{ Japan } & \multicolumn{4}{c|}{ Hong Kong } \\
\hline Error-Producing Conditions (EPC) & Total & Error-Producing Conditions (EPC) & Total \\
\hline EPC17 & Inadequate Checking & 16 & EPC17 & Inadequate Checking & 17 \\
\hline EPC2 & Time shortage & 12 & EPC14 & $\begin{array}{l}\text { Delayed/incomplete } \\
\text { feedback }\end{array}$ & 15 \\
\hline EPC26 & Progress tracking lack & 10 & EPC26 & Progress tracking lack & 15 \\
\hline EPC16 & $\begin{array}{l}\text { Impoverished } \\
\text { information }\end{array}$ & 9 & EPC2 & Time shortage & 12 \\
\hline EPC15 & Operator inexperience & 7 & EPC15 & Operator inexperience & 11 \\
\hline EPC14 & $\begin{array}{l}\text { Delayed/incomplete } \\
\text { feedback }\end{array}$ & 7 & EPC16 & Impoverished information & 10 \\
\hline EPC13 & Poor feedback & 5 & EPC13 & Poor feedback & 7 \\
\hline EPC10 & Knowledge transfer & 5 & EPC11 & Performance ambiguity & 5 \\
\hline EPC19 & No diversity & 5 & EPC24 & $\begin{array}{l}\text { Absolute judgements } \\
\text { required }\end{array}$ & 4 \\
\hline EPC24 & $\begin{array}{l}\text { Absolute judgements } \\
\text { required }\end{array}$ & 5 & EPC23 & Unreliable instruments & 3 \\
\hline
\end{tabular}




\begin{tabular}{|c|l|c|c|l|c|}
\hline \multicolumn{4}{|c|}{ Japan } & \multicolumn{4}{c|}{ Hong Kong } \\
\hline Error-Producing Conditions (EPC) & Total & Error-Producing Conditions (EPC) & Total \\
\hline EPC36 & Task pacing & 5 & EPC7 & Irreversibility & 2 \\
\hline EPC33 & Poor environment & 4 & EPC20 & Educational mismatch & 2 \\
\hline EPC23 & Unreliable instruments & 3 & EPC22 & Lack of experience & 2 \\
\hline EPC5 & $\begin{array}{l}\text { Spatial and functional } \\
\text { incompatibility }\end{array}$ & 2 & EPC35 & Sleep cycles disruption & 2 \\
\hline EPC35 & Sleep cycles disruption & 2 & EPC36 & Task pacing & 2 \\
\hline EPC1 & Unfamiliarity & 1 & EPC5 & $\begin{array}{l}\text { Spatial and functional } \\
\text { incompatibility }\end{array}$ & 1 \\
\hline EPC12 & Misperception of risk & 1 & EPC10 & Knowledge transfer & 1 \\
\hline EPC18 & Objectives conflict & 1 & EPC12 & Misperception of risk & 1 \\
\hline EPC30 & Ill-health & 1 & EPC18 & Objectives conflict & 1 \\
\hline Japan Total & $\mathbf{1 0 1}$ & EPC27 & Physical capabilities & 1 \\
\hline Hong Kong Total & $\mathbf{1 1 5}$ & EPC30 & Ill-health & 1 \\
\hline
\end{tabular}

In the Human Error Probability calculation, the number of EPC that obtain in the cases is relatable for the final result of the calculation. The more EPCs are obtained, the higher of Human Error Probability final calculation result.

\subsection{Human Error Probability}

The figures below are the result of Human Error Probability (HEP) calculation for Japan and Hong Kong. The result of calculation is between 0 and 1 , which means that there are other factors that influenced the accidents and if the result is 1 , that accident is definitely because of human factors. Bad weather is one of the factors that causes the accident.

Fig. 2 shows the result calculation of HEP of Japanese accidents. From 27 cases that had been analyzed, there are 3 cases that definitely because of negligence of seafarers, human factors. Meanwhile in Fig. 3 shows the result of Hong Kong accidents. There are 4 cases of 21 cases that had been analyzed which had the final result of HEP calculation are 1, definitely because of human factors. Furthermore, the average result of HEP in Hong Kong is higher than in Japan, it is influenced by the number of EPC that obtained, the more EPC obtained, the result of HEP is higher.

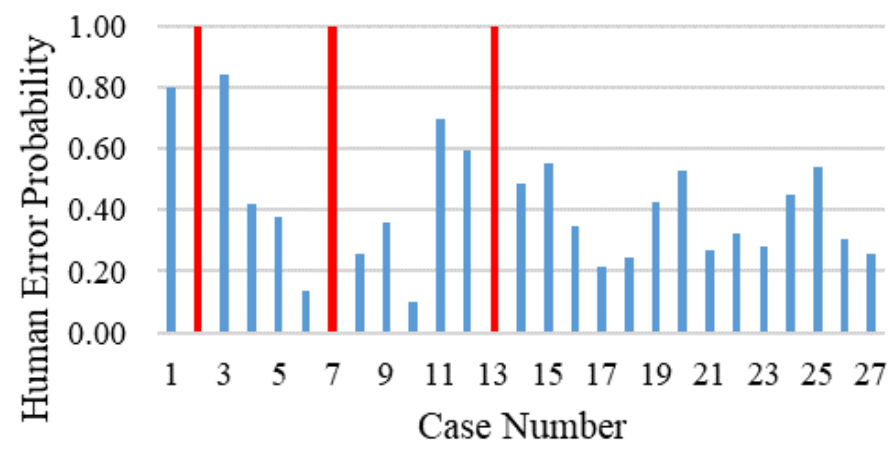

Figure 2: Human Error Probability in Japan. 


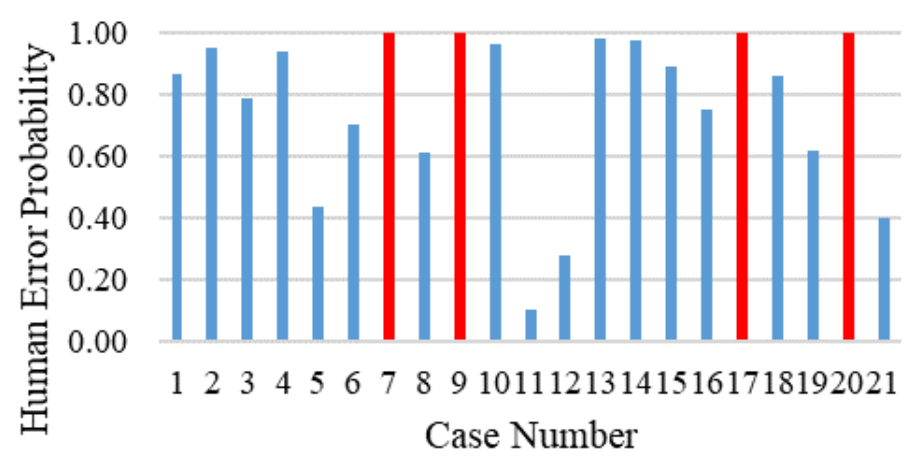

Figure 3: Human Error Probability in Hong Kong.

\section{DISCUSSIONS AND CONSIDERATIONS}

Every year, both in Japan and Hong Kong there are maritime accidents that occurred, and the highest frequency of accidents type is collision. It is proved by the government official report which published monthly and annually. In the navigation bridge, the functions and responsibility of seafarers are delivering cargo or passenger on time by conducting the safety navigation. According to COLREG, Rule 5, the definition of look-out is maintaining a proper look-out by sight and hearing as well as by all available means appropriate in the prevailing circumstances and conditions so as to make full appraisal of the situation and of the risk of collision [4]. It means that seafarers have to pay attention to everything during sailing and have to use all of that information continuously to assess the situation and the risk of collision. All of information during sailing is obtained by using the navigational equipment as well, such as ECDIS, ARPA, radio and so on.

In these cases, both in Japan and Hong Kong, the seafarers were late to notice that their ship were heading to the accidents because of improper look-out, it is shown as EPC 17, EPC 26, EPC 23, therefore the seafarers were shortage of time (EPC 2) to avoid the collision. Furthermore, the communication among seafarers in the navigational bridge is very important to prevent the accidents, it is shown by the EPC 13, EPC 14, EPC 16 and EPC 19. Poor communication can influence the master to take a wrong judgement because of misunderstanding the situation [15]. In these cases, there were seafarers who maintain the look-out without supervision of the Master, meanwhile the seafarer himself was not confident with their ability due to lack of experience and knowledge. This condition has to be informed to the Master well (EPC 15). And also, among the seafarers has to give good and clear feedback, the communication is very important to prevent to choose some wrong judgements to prevent the collision (EPC 11, EPC 12, EPC 18, EPC 19 and EPC 24).

It is in line with the Chauvin in 2013 who applied the HFACS framework to analyze 27 recent collision cases involving 39 vessels, he found that the collisions occurred because of decision errors, which supported by the poor visibility and misuses of instrument, loss of situation awareness or poor attention and poor communication among seafarers in bridge Resources Management [16]. Both HFACS framework and HEART methodology proceed the same results of error producing conditions for analyzing collision.

\section{CONCLUSIONS}

The conclusions of this study are as follow: 
1) The causes of collision accidents both in Japan and Hong Kong are inadequate checking of progress which causes time shortage to make judgements to avoid the collision. The well communication among the seafarers while doing proper look-out should be required.

2) The type of vessel which involve in Japan and Hong Kong and the generic task that obtained are different, meanwhile the error-producing conditions which causes the collision accidents are mostly the same.

3) HEART methodology can be applied to assess collision accident well. The result of HEART methodology to assess the collision proceed the same result as HFACS framework.

\section{References}

[1] C. G. Soares and A. P. Teixeira, "Risk assessment in maritime transportation," Reliab. Eng. Syst. Saf., vol. 74, no. 3, pp. 299-309, 2001.

[2] A. Graziano, A. P. Teixeira, and C. Guedes Soares, "Classification of human errors in grounding and collision accidents using the TRACEr taxonomy, ”Saf. Sci., vol. 86, pp. 245-257, 2016.

[3] P. Sotiralis, N. P. Ventikos, R. Hamann, P. Golyshev, and A. P. Teixeira, "Incorporation of human factors into ship collision risk models focusing on human centred design aspects,” Reliab. Eng. Syst. Saf., vol. 156, pp. 210227, 2016.

[4] M. Ventura, "COLREGS -International Regulations for Preventing Collisions at Sea COLREGS -International Regulations for Preventing Collisions at Sea COLREGS -International Regulations for Preventing Collisions at Sea-Articles of the Convention on the International Re," pp. 1-74, 2009.

[5] E. Eleftheria, P. Apostolos, and V. Markos, "Statistical analysis of ship accidents and review of safety level," Saf. Sci., vol. 85, pp. 282-292, 2016.

[6] J. C. Williams, "A data-based method for assessing and reducing human error to improve operational performance," in Conference Record for 1988 IEEE Fourth Conference on Human Factors and Power Plants, 1988, pp. 436-450.

[7] B. Kirwan, H. Gibson, R. Kennedy, J. Edmunds, G. Cooksley, and I. Umbers, "Nuclear action reliability assessment (NARA): a data-based HRA tool," Saf. Reliab., vol. 25, no. 2, pp. 38-45, Jun. 2005.

[8] B. Kirwan and W. Gibson, "Controller Action Reliability Assessment ( CARA) CARA User Manual," no. August, pp. 1-70, 2009.

[9] W. Gibson, A. Mills, S. Smith, and B. Kirwan, Railway action reliability assessment, a railway-specific approach to human error quantification. 2013.

[10] E. Akyuz, M. Celik, and S. Cebi, "A phase of comprehensive research to determine marine-specific EPC values in human error assessment and reduction technique," Saf. Sci., vol. 87, pp. 63-75, 2016.

[11] L. P. Bowo and M. Furusho, "Human error assessment and reduction technique for marine accidents analysis: the case of ship grounding,” 2016, pp. 193-201.

[12] L. P. Bowo and M. Furusho, "Human Error Assessment and Reduction Technique for Reducing the Number of Marine Accidents in Indonesia," Appl. Mech. Mater., vol. 874, pp. 199-206, 2018.

[13] L. P. Bowo and M. Furusho, "Analyzing the occupational accidents in Australia Maritime Accidents using Human Error Assessment and Reductive Technique (HEART) Methodology," 2017.

[14] B. Kirwan, "The validation of three human reliability Quantification techniques - THERP, HEART and JHEDI: Part III - practical aspects of the usage of the techniques," Appl. Ergon., vol. 28, no. 1, pp. 27-39, 1997.

[15] W. Mutmainnah and M. Furusho, "4M Overturned Pyramid (MOP) Model Utilization: Case Studies on Collision in Indonesian and Japanese Maritime Traffic Systems (MTS),” TransNav, Int. J. Mar. Navig. Saf. Sea Transp., vol. 10, no. 2, pp. 257-264, 2016.

[16] C. Chauvin, S. Lardjane, G. Morel, J. P. Clostermann, and B. Langard, "Human and organisational factors in maritime accidents: Analysis of collisions at sea using the HFACS," Accid. Anal. Prev., vol. 59, pp. 26-37, 2013. 